\section{Health-related quality of life in patients with chronic leg ulcers in a developing country}

\author{
Ganiyu Oyediran Oseni, ${ }^{1}$ \\ Cletus Ikechukwu Otene, ${ }^{2}$ \\ Peter Babatunde Olaitan, ${ }^{1}$ \\ Adesina Ajibade, ${ }^{3}$ Olawale Adebayo \\ Olakulehin, ${ }^{3}$ David Adekunle Onilede ${ }^{4}$ \\ ${ }^{1}$ Burns and Plastic Surgery Unit, \\ Ladoke Akintola University of \\ Technology Teaching Hospital, Osogbo, \\ Osun State; ${ }^{2}$ Department of Surgery, \\ Delta State University, Abraka, Delta \\ State; ${ }^{3}$ Orthopaedic surgery Unit, \\ Ladoke Akintola University of \\ Technology Teaching Hospital, \\ Ogbomoso, Oyo State; ${ }^{4}$ Burns and \\ Plastic surgery Unit, Ladoke Akintola \\ University of Technology Teaching \\ Hospital, Ogbomoso, Oyo State, Nigeria
}

\begin{abstract}
Poverty with inadequate care prolongs duration of ulcers healing with attendant complications. The impact of this on the quality of life of patients in an economic depleted environment needs to be evaluated. Quality of life of patients with chronic leg ulcers was assessed using validated Cardiff wound impact schedule questionnaires in two teaching Hospitals in Nigeria. The result was analyzed using SPSS Version 17 with frequencies and means. Post traumatic ulcers were the most common cause of chronic leg ulcers (33.7\%), followed by diabetes mellitus $(31.3 \%)$,venous ulcers $(16.9 \%)$, and sickle cell ulcers $(4.8 \%)$. Tropical ulcers and others like vasculitis and chronic osteomyelitis accounted for $13.3 \%$. The ulcers have deleterious effects on the patients' occupation, finances, mobility and social interaction with negative self-image. All the symptoms due to the inadequate facilities and materials for care, leg ulcers being a chronic disease that demands a long duration of treatment, with materials that are expensive but have to be purchased by the poor patients, who most of the time could not afford them. Unfortunately, again, practice of health insurance is often poor in most of the developing countries and patients have to pay out of pocket for their care. Often, many resorts to unorthodox method of care which further prolongs the healing period and make the patients susceptible to complications and loss of job and social interaction. The current study is aimed at assessing the impact of chronic leg ulcers on the quality of life of these patients using structured questionnaires and Cardiff wound impact schedule as the instruments of assessment and to identify the factors responsible for reduction in quality of life. ${ }^{4}$ This would be used as a basis for organizing health education and proper planning for the management of leg ulcer patients in our society.
\end{abstract} assessed significantly correlated with overall quality of life (QoL). However, physical symptoms dimension is the most highly correlated with QoL score, followed by social life dimension. The least correlated is wellbeing dimension. Symptoms associated with chronic leg ulcer tend to have negative impact on quality of life of these patients. Therefore, these should be borne in mind and incorporated in the management of these patients.

\section{Introduction}

Skin ulcers on the legs have a chronic, relapsing course and are often a significant management challenge. Highly exuding wounds are common, can result in malodour, pain, maceration, infection and unsightly soiled dressings, which can have a negative impact on an individual's quality of life. ${ }^{1}$ It has been observed that despite appropriate treatment of underlying pathologies and wound care practice, a significant proportion of chronic wounds still fail to heal. ${ }^{2}$

Patients with chronic leg ulcers, therefore, have significantly more pain, more restrictions regarding social functions, less vitality, and limitations with respect to emotional roles compared to the respective controls. Other problem areas which have been identified include restrictions in work capacity, recreation, social interaction, psychological well-being, as well as problems caused by treatment regimens. ${ }^{3}$ The treatment of chronic leg ulcers remains a big burden to the patients especially in Nigeria,

\section{Materials and Methods}

This was a cross sectional study of chronic leg ulcer patients who presented to the Plastic surgery units of Ladoke Akintola University of Technology Teaching Hospital, Osogbo, Nigeria and Delta state University, Asaba, Nigeria between August 2012 and August 2013. All adult patients who presented with chronic leg ulcers and who consented to be involved in this study were recruited following ethical approval
Correspondence: Ganiyu. Oyediran Oseni, Burns and Plastic Surgery Unit, Ladoke Akintola University of Technology Teaching, Hospital, Osogbo, Osun State, Nigeria.

Tel.: +2348032950477

E-mail: osenioyediran@yahoo.co.uk

Key words: Chronic leg ulcers, Quality of life, Developing Countries, Cardiff wound impact, Depression.

Contributions: OGG participated in the management of the patients, designing and administering the questionnaires, analyzing and writing up the manuscript; OCI took part in the administration of questionnaires and participated in designing, analyzing and writing up the manuscript. OPB took part in the management of the patients and participated in the design, analysis and write up of the manuscript; AA participated in the management of the patients, designing and administering the questionnaires, analyzing and writing up the manuscript; OOA took part in the design, analysis and write up of the manuscript; ODA took part in the design, analysis and write up of the manuscript.

Conflict of interest: The authors declare no conflict of interest.

Ethics approval and consent to participate: Not required.

Received for publication: 16 December 2019 Revision received: 12 February 2020 .

Accepted for publication: 12 February 2020.

This work is licensed under a Creative Commons Attribution NonCommercial 4.0 License (CC BY-NC 4.0).

(C) Copyright: the Author(s), 2019

Licensee PAGEPress, Italy

Pyramid Journal of Medicine 2020; $3: 33$

doi:10.4081/pjm.2020.33

from Ladoke Akintola University of Technology, College of Health Sciences Institution Review Board. Patients with leg ulcers that persist for more than six weeks and show no tendency of healing after 3 or more months are considered chronic ulcers. All patients above 16 years presenting with leg ulcers of more than six weeks duration and consent to take part in the study are included whereas, patients that are less than 16 years, refused to give consent or have incomplete questionnaires are excluded from the study.

Structured questionnaires and Cardiff wound impact schedule were administered to the patients over the period. The questionnaires documented the Bio-data, types of ulcers, effects of ulcers on the patients, as well as quality of life of the patients. The 
Cardiff wound impact schedule (CWIS), which has been validated in Nigeria, measures three dimensions, namely: physical symptoms and daily living, social life and well-being. Data analysis was performed with SPSS Version 17. Frequencies and percentages were calculated. Response categories were scored from 1 (the least desirable) to 5 (the most desirable) ranging from Always to Not at all, Very to Not at all and Strongly agree to Strongly disagree for the physical symptoms and daily living, social life and wellbeing dimensions respectively. The scores were summed to obtain quality of life score for each dimension and an overall quality of life score from the sum of all dimension scores. In accordance with the number of items in each dimension the range of total obtainable score was 7-35 for the social life and wellbeing dimensions, 12-60 for the physical symptoms and daily living dimension and 26-130 for the overall quality of life score.

\section{Results}

A total of 83 patients with chronic leg ulcers were involved attending the surgical outpatient clinic or admitted into the two hospitals were involved in this study. Their ages ranged between 18 and 83 years (mean of $45.46 \pm 17.45$ years). Patients of less than 40 years of age was the most commonly affected $(36,43.4 \%)$, followed by age range $40-64$ years $(34,41.0 \%)$ while patients 65 years and above were 13 (15.7\%).

\section{Socio demographic characteristics}

There were $50(60.2 \%)$ males and 33 $(39.8 \%)$ females. Their ages ranged between 18 and 83 years (mean of $45.46 \pm 17.45$ years). Fifty-seven $(68.7 \%$ ) of the patients were married, $23(27.7 \%)$ were single, $3(3.6 \%)$ were divorced. Thirty-five $(42.2 \%)$ of them were traders/businessmen and women, 12 (14.4\%) were artisans, 10 $(12.0 \%)$ each were students and unemployed/retirees, $6(7.2 \%)$ were civil servants, $4(4.8 \%)$ farmers, $3(3.6 \%)$ teachers and $3(3.6 \%)$ were clergy men (Table 1$)$.

\section{Etiology and duration of ulcers}

Post-traumatic ulcers constitute the largest subgroup $28(33.7 \%)$, followed by diabetic leg and foot ulcers $26(31.3 \%)$ of the patients. Venous ulcers 14 (16.9\%), sickle cell and malignant ulcers with 4 (4.8\%) each, tropical and other ulcers like vasculitis, rheumatoid arthritis, chronic osteomyelitis constitute about 7 (8.5\%). Ulcers involved only the left legs in 37 (44.6\%), right leg alone in $36(43.4 \%)$ and both legs in $10(12.0 \%)$ (Table 1$)$.
Ulcers' duration showed that 41 (49.4\%) were present for less than one year, $24(28.9 \%)$ for $1-3$ years, $8(9.6 \%)$ for $4-10$ years and $10(12.0 \%)$ for more than 10 years.

\section{Socio-demographic characteristic of leg ulcers}

While $8(9.6 \%)$ of the patients did not have any formal education, $26(31.3 \%)$ had primary education, $33(39.8 \%)$ had secondary education, and $16(19.3 \%)$ had up to tertiary education. Only $15(18.1 \%)$ of the patients lived alone, while $68(81.9 \%)$ of them lived with other people in the house. Twenty-two $(26.5 \%)$ of the patients lived in one room apartment, 57 (68.7\%) lived in flats, while $4(4.8 \%)$ lived in duplex houses. Location of their habitation revealed 12

Table 1. Socio-demographic characteristic of leg ulcers.

\begin{tabular}{lcc} 
Factors & Prequency (n) & Percentage (\%) \\
Sex & & 60.2 \\
Male & 50 & 39.8 \\
Female & 33 & \\
Marital status & & 68.7 \\
Married & 57 & 27.7 \\
Single & 23 & 3.6 \\
Divorced & 3 & \\
\hline Occupation & & 42.2 \\
Trading & 35 & 14.4 \\
Artisan & 12 & 12.0 \\
Schooling & 10 & 12.0 \\
Unemployed & 10 & 7.2 \\
Civil service & 6 & 4.8 \\
Farming & 4 & 3.6 \\
Teaching & 3 & 3.6 \\
Clergy & 3 & \\
Education & & 9.6 \\
None & 8 & 31.3 \\
Primary & 26 & 39.8 \\
Secondary & 33 & 19.3 \\
Tertiary & 16 & \\
& & \\
\hline
\end{tabular}

Table 2. Socio-demographic characteristic of leg ulcers.

\begin{tabular}{lcc}
\hline Factors & Frequency (n) & Percentage (\%) \\
Habitation & & \\
$\quad$ Live alone & 15 & 18.1 \\
$\quad$ Live with family member & 68 & 81.9 \\
Nature of house & 22 & 26.5 \\
$\quad$ One room apartment & 57 & 68.7 \\
$\quad$ Flat & 4 & 4.8 \\
$\quad$ Duplex & 12 & \\
\hline Location of habitation & 71 & 14.5 \\
$\quad$ Village & & 85.5 \\
$\quad$ Major town/cities & 26 & 31.3 \\
$\quad$ Type of ulcers & 28 & 33.7 \\
Diabetes mellitus & 14 & 16.9 \\
$\quad$ Traumatic & 4 & 4.8 \\
$\quad$ Venous & 11 & 13.3 \\
$\quad$ Sickle cell & & \\
Tropical ulcers and others like infective & & \\
ulcers, Vasculitis and Osteomyelitis &
\end{tabular}

$(14.5 \%)$ lived in villages, $71(85.5 \%)$ lived in major towns or urban areas (Table 2).

\section{Physical symptoms dimension}

Only $19(22.9 \%)$ of the patients did not have their sleep disturbed while the others have a range of disturbance to their sleep. Forty-four $(53.0 \%)$ of the patients were ambulant, 23 (27.7\%) had their mobility slightly hindered while $16(19.3 \%)$ of them were bedridden (Table 3 ).

Pain was the most common symptom (62 or $74.7 \%$ ) reported among the patients with $26(31.3 \%)$ having only pain while 36 $(43.4 \%)$ others have pain in addition to other symptoms. Other symptoms include exudation, only $13(15.7 \%)$, exudation with other symptoms, 26 (31.3\%); depression interested only 3 respondents (3.6\%), while 
depression in addition to other symptoms was reported by $26(31.3 \%)$. Insomnia only was reported by $1(1.2 \%)$ patient and in addition to other symptoms by 18 (24.1\%) patients (Figure 1).

Leakage from the wound and difficulty from bandaging/dressing were only absent among $8(9.6 \%)$ of the patients while all the rest have leakages and difficulty from bandaging at varying degrees. Unpleasant odor or smell from the wounds was reported by $73(88.0 \%)$ of the patients while varying degree of problems from everyday task such as shopping was reported by 55 $(66.3 \%)$ of the patients. Difficulty in finding appropriate foot wear was reported by 50 $(60.2 \%)$ while only $33(39.8 \%)$ reported having no such difficulty.

Problems with the amount of time needed to care for the wound site was reported to be absent only by $11(13.2 \%)$ while the remaining $72(86.7 \%)$ reported varying degrees of problem with the amount of time needed to care for the wound. Finally, financial difficulty as a result of the wound was reported as absent by only $38(45.8 \%)$ of the patients. Seventy-one $(85.5 \%)$ of the patients reported that the leg ulcers affect their job and indeed $54(65.1 \%)$ of the patients have lost their jobs at one time or another because of the leg ulcers (Table 3).

Sixty-one $(73.5 \%)$ of the leg ulcers' patients have had the ulcers affecting their finances and $67(80.7 \%)$ found the ulcers burdensome. Only $16(19.3 \%)$ of the patients never got angry about the ulcers while only $21(24.1 \%)$ never had fear concerning the ulcers. Sixty-one $(73.5 \%)$ of the patients have one level of social isolation or another while $44(53.1 \%)$ of the patients have some forms of depression and 59 $(71.1 \%)$ have varying levels of negative self-image.

\section{Social life dimension}

Sixty-nine $(83.1 \%)$ of the patient reported varying level of difficulty in getting around while 14 (16.9\%) never had any such difficulty (Table 4). Sixty-eight $(81.9 \%)$ of the patients relied more on others while $15(18.1 \%)$ never had to rely on anybody. Family and friends were reported as being protective among 63 (75.9\%) while $20(24.1 \%)$ of the patients reported there was no such protection from the family/friends. Fifty-eight $(69.9 \%)$ of the patients also reported being unable to enjoy their usual social life while 25 (30.1\%) gave a contrary report. Desire to withdraw from people was the most commonly reported social life dimension among $67(80.7 \%)$ of the patients while only $6(7.2 \%)$ did not report any such desire (Table 4).

Finally, the mean social life dimension was 19.786.29 with a minimum of 7 and a maximum of 32 . The mean well being dimension was $19.98 \pm 3.47$ with a minmum of 8 and maximum of 27 while the mean

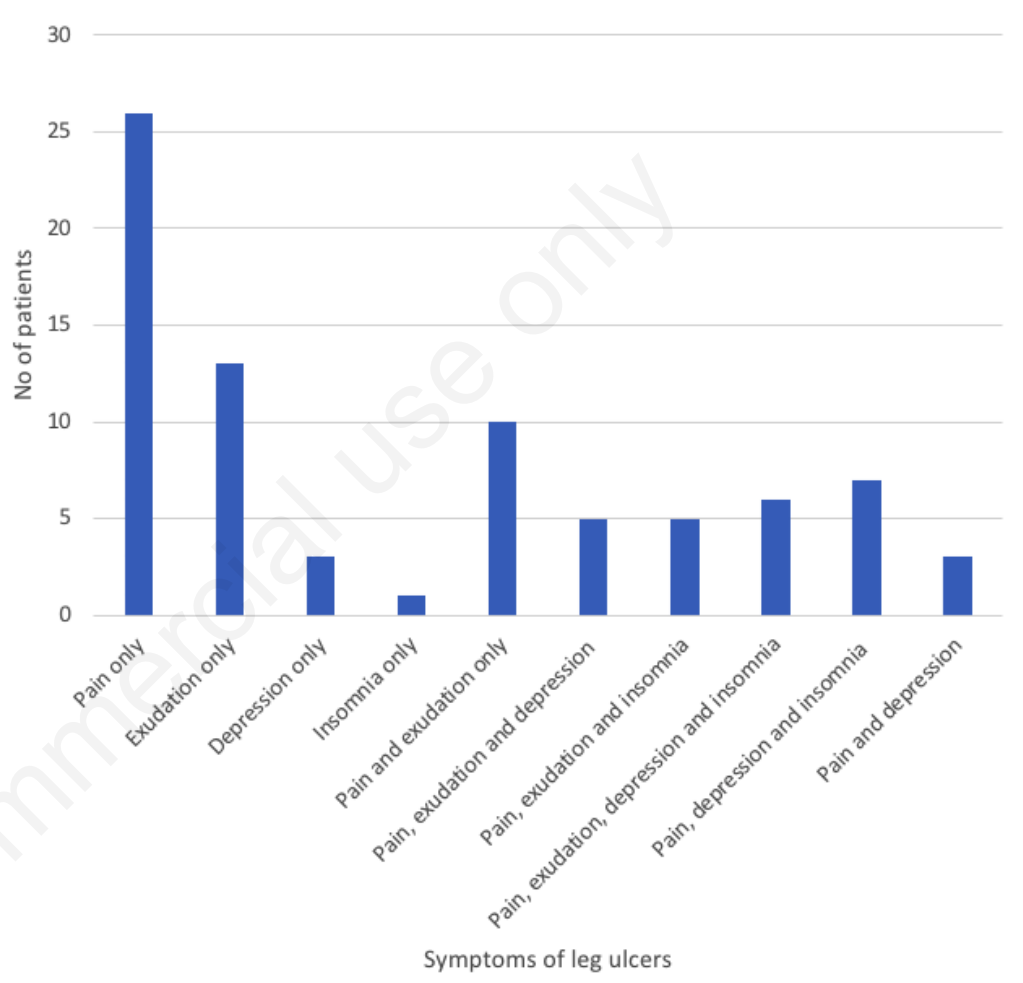

Figure 1. Symptoms associated with leg ulcers.

Table 3. Physical symptoms and daily living.

\begin{tabular}{|c|c|c|c|c|c|}
\hline How stressful has it been for you in the last seven days & Always & Frequently & Sometimes & Seldom & Not at all \\
\hline Disturbed sleep & 19 & 13 & 17 & 15 & 19 \\
\hline Difficult bathing & 26 & 13 & 14 & 8 & 22 \\
\hline Immobility outside the home & 40 & 9 & 9 & 9 & 16 \\
\hline Immobility around the home & 33 & 15 & 13 & 4 & 18 \\
\hline Leakage from the wound & 24 & 29 & 15 & 7 & 8 \\
\hline Associated pain & 61 & 9 & 8 & 5 & 0 \\
\hline Difficulty from bandaging/dressing & 35 & 21 & 10 & 9 & 8 \\
\hline Unpleasant odour from wound site & 44 & 15 & 9 & 5 & 10 \\
\hline Problem from every day task e.g. shopping & 23 & 16 & 5 & 11 & 28 \\
\hline Difficulty in finding appropriate foot wear & 24 & 10 & 8 & 8 & 33 \\
\hline Problem with amount of time needed for care of the wound & 28 & 21 & 13 & 10 & 11 \\
\hline Financial difficulty from the wound & 12 & 8 & 14 & 11 & 38 \\
\hline
\end{tabular}


physical symptoms dimension was $31.26 \pm 9.43$ (minimum 15 and maximum 53). Overall, mean quality of life score was $71.02 \pm 9.43$ with a minimum of 42 and maximum of 98. All the three dimensions are significantly correlated with overall quality of life (QoL) score. However, physical symptoms dimension is the most highly correlated with QoL score, closely followed by social life dimension. The least correlated is well-being dimension.

Age does not have a linear relationship with overall quality of life score. Attempts at transformation (log, reciprocal, square root, power) were made, but non-linearity persisted. Consequently, age was categorized so that it could be included in the multiple linear regression model.

There was a lack of linear relationship between over-all quality of life score and age. This is further depicted in the scatter plot (Figure 2).

\section{Discussion}

Chronic leg ulcers are a major challenge in the developing world. Often, patients carry these ulcers over a very long period with devastating morbidity and loss of man hour to the care of the ulcers and to the associated morbidity. Chronic leg ulcer impacts the quality of life in a number of ways such as reduced mobility, pain, unpleasant odor, sleep disturbances, social isolation, among others. ${ }^{5}$ In developing countries like Nigeria, chronic leg ulcers are commonly seen among the populace who have not treated the ulcers properly as a result of poor understanding, poor facilities and poverty.

There are few reports in the literature on the effect of chronic leg ulcers and its associated problems on the quality of life of patients in the developing countries like Nigeria. Leg ulceration is a common, chronic, recurring condition and chronic leg ulcers are major health problem in Western countries. The treatment of chronic leg ulcers remains a formidable challenge in many patients. This often leads to reduction in health-related quality of life and physical activities apart from the financial burden on the family.

The current study evaluated the healthrelated quality of life of patients with leg ulcers. These patients cut across different socio-economic, professional and educational strata (Table 1). Traumatic ulcers $(33.7 \%)$ were the most common form of leg ulcers in this study. This is similar to previous reports by Rahman and Shukla. ${ }^{6,7}$ This may be as a result of low incidence of vas-

\section{Scatterplot of overall quality of life score of patients against age of patients}

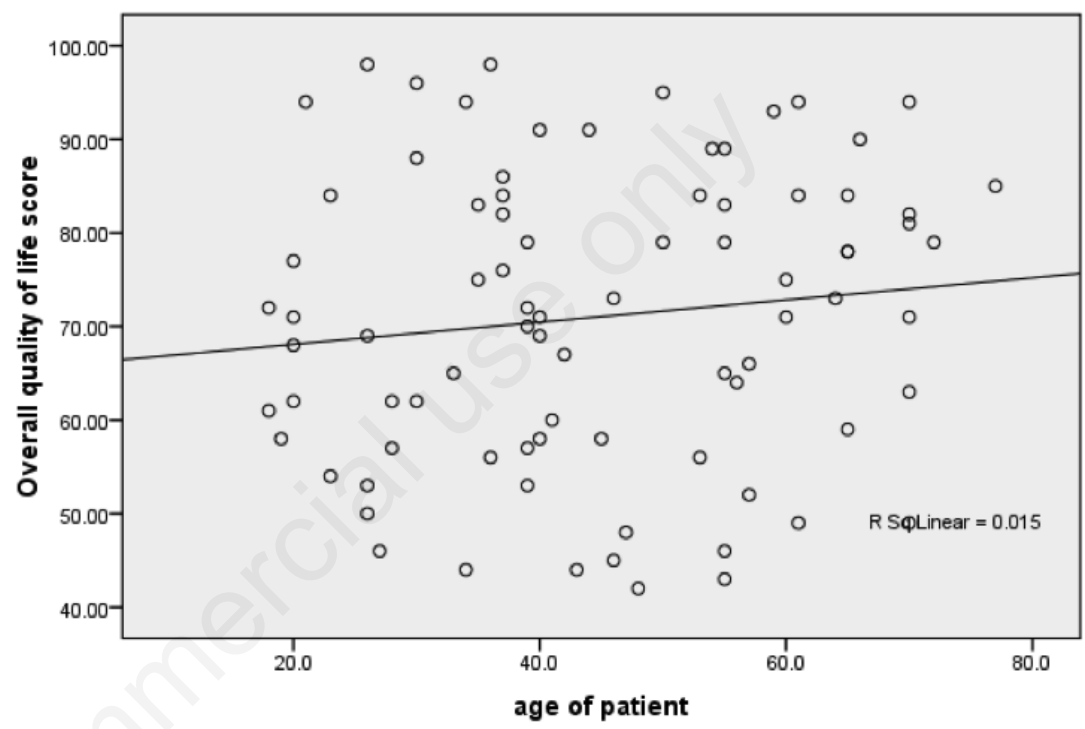

Figure 2. Scatterplot of overall quality of life score of patients against age of patients.

Table 4. Social life dimension and wellbeing.

\begin{tabular}{|c|c|c|c|c|c|}
\hline How stressful has it been for you in the last seven days & Very & Quite a bit & Moderately & Slightly & Not at all \\
\hline \multicolumn{6}{|l|}{ Social life dimension } \\
\hline To get out and around & 26 & 19 & 11 & 13 & 14 \\
\hline Relying more on others & 27 & 11 & 22 & 8 & 15 \\
\hline Family/friends over protective & 16 & 15 & 12 & 19 & 20 \\
\hline Unable to enjoy your usual social life & 14 & 11 & 17 & 16 & 25 \\
\hline Limited contact with family/friends & 16 & 16 & 24 & 10 & 17 \\
\hline Not going out for fear of bumping your wound site & 20 & 17 & 22 & 11 & 13 \\
\hline Wanting to withdraw from people & 31 & 18 & 18 & 10 & 6 \\
\hline Well-being & Strongly agree & Agree & Not sure & Disagree & Strongly disagree \\
\hline I feel anxious about my wound & 6 & 11 & 55 & 10 & 1 \\
\hline I feel frustrated with the time it is taking for the wounds to heal & 9 & 14 & 47 & 12 & 1 \\
\hline I am confident that the wounds I have will heal & 4 & 12 & 62 & 5 & 0 \\
\hline I worry that I may get another wound in future & 17 & 19 & 20 & 27 & 0 \\
\hline The appearance of the wound site is upsetting to me & 8 & 11 & 42 & 22 & 0 \\
\hline I worry about bumping the wound site & 11 & 11 & 35 & 24 & 2 \\
\hline I worry about the impact of the wound(s) on my family/friends & 6 & 6 & 58 & 10 & 3 \\
\hline
\end{tabular}


cular diseases and high incidence of vehicular accident and other traumatic injuries in the developing countries. This is followed by diabetic leg and foot ulcers (31.3\%).

It has been observed that a significant proportion of chronic wounds fail to heal in response to treatment of underlying pathologies combined with good wound care practice. $^{2}$ Indeed, current treatment modalities for chronic leg ulcers are time consuming, expensive, and only moderately successful. ${ }^{8}$

A substantial proportion of patients in this study felt that leg ulcer treatments caused pain ${ }^{9}$ and suggested that efforts should be made to reduce pain in this group of patients. ${ }^{2}$ The current study reveals pain as the commonest associated problem in leg ulcers among $79.5 \%$ of the patients (Table 2 ). Wound pain has been observed to be a serious problem for elderly patients suffering from chronic leg ulcers, and it may lead to reduced wound healing rates and reduced quality of life. ${ }^{10}$

Our current study revealed depression as occurring among $33.6 \%$ of the patients. This confirms a previous observation by Wales that depression is common in people with chronic wound pain. ${ }^{11-13}$

In this study, the burden of the chronic leg ulcers on the finance of the patients was seen in $71(85.5 \%)$ of the patients. This is mainly because most of the patients do not have health insurance coverage and have to pay out of pocket, from pension or rely on family for the care of their ulcers. In addition, patients were mostly of low socio-economic status and a prolonged period of treatment creates a significant financial and career burden with regards to cost of management and time taken from employment and family responsibilities. This finding is consistent with the previous reports by Nelzen and Edwards on the financial burden on chronic leg ulcer patients and their relatives. ${ }^{8,9}$

Venous ulcers have been described as a major health problem because of the increased costs of treatment and the refractory nature of the ulcers. The treatment cost is estimated to be around 1 billion dollars per year in the United States (US), and the average cost for one patient over a lifetime exceeds dollars 400,000. ${ }^{14}$

There was significant physical disturbance of the majority of the people who had chronic leg ulcers as well as problems with morbidity around the home and reduced mobility outside the home.

The majority $72(86.7 \%)$ of the patients also reported problems with the amount of time needed to care for the wound site as many of the patients spend a lot of time daily in taking care of the ulcers either at home or in a nearby health facility.

Finally, financial difficulty as a result of the wound was reported as absent by only $38(45.8 \%)$ of the patients. Most $71(85.5 \%)$ of the patients in this study report that the leg ulcers affect their jobs. Loss of job was also seen among many $54(65.1 \%)$ of the patients suggesting reduced financial resources to a group of people who have chronic wounds and with no health insurance, as health insurance is not very common in the country.

A study in Netherland ${ }^{15}$ shows major problems with leg ulcer patients being pain (85\%), outdoor mobility (47\%) and problems in finding appropriate footwear $(60 \%)$ with statistical analysis showing no differences between patients with ulcers based on a venous etiology and ulcers based on mixed etiology.

The feelings of the patients show anger, fear, depression, negative self-image and stress.

It has been observed ${ }^{16}$ that it is not uncommon to find that patients with venous leg ulcers have a reduced quality of life.

In spite of the aforementioned effects of the ulcers on the patients, many of the patients agree that the ulcers will heal. Most of the patients with leg ulcers in this study tend to have significant pain, exudates, less ambulant, more untoward effects on occupation, more stress, more restrictions regarding social functioning, and less vitality. Other problem areas, which have been identified, include financial burden, restrictions in work capacity, recreation, social interaction and activities, anxiety, and feeling of frustration. Psychological well-being, as well as problems caused by treatment, and psychological factors, including depression, should be a focus in assessment and ongoing review of patients with leg ulceration. ${ }^{17}$

These physical and psychological problems should be borne in mind in managing these patients and efforts should be made to alleviate them. The use of groups like leg ulcers group, though may be of help as a study has revealed that Club model appears to be more cost-effective than traditional home nursing for the treatment of ulcers. ${ }^{18}$ It has been suggested that, increased awareness of the psychosocial dynamic in elderly patients should be integral to the wound care protocol. ${ }^{19}$

Also observed is that improved ulcer care reduced considerably the annual costs of wound management. ${ }^{20}$ With improved ulcer care, the adverse symptoms and signs associated with leg ulcers are expected to reduce as this has been observed elsewhere with patients suffering from leg ulceration show modest improvements in perceived health following 12 weeks of care. Improvements in practice may enhance the magnitude of these improvements ${ }^{21}$ and this should be vigorously pursued by physicians taking care of patients with leg ulcers. Effective and timely intervention should be given when treating patients with chronic leg ulcers. The need for leg ulcer group is also emphasized to improve interaction of patients with leg ulcers.

\section{Conclusions}

Pain has been found to be a major factor responsible for the delay in wound healing and reduction in socialization and quality of life of patients with chronic leg ulcers. Therefore, control of pain, implementation of leg ulcer group and improvement in health care insurance coverage to all cadres of citizen in developing countries will contribute immensely to the improvement in quality of life of these patients.

\section{References}

1. Jones J, Barraud J. An evaluation of Kerra Max. Care in the management of moderate to heavily exuding wounds. Br J Community Nurs 2014;19:S48-3.

2. Moore K, McCallion R, Searle RJ, et al. Prediction and monitoring the therapeutic response of chronic dermal wounds. Int Wound J 2006;3:89-96.

3. Herber OR, Schnepp W, Rieger MA. A systematic review on the impact of leg ulceration on patients' quality of life. Health Qual Life Outcome 2007;5:44.

4. Price P, Harding K. Cardiff Wound Impact Schedule: The development of a condition specific questionnaire to assess health related quality of life in patients with chronic wounds of the lower limb. Int Wound J 2004;1:10e7. 5. Brtan Romić R, Brtan A, Romić I, et al. Quality of life and perception of disease in patients with chronic leg ulcer. Acta Clin Croat 2015;54:309-14.

6. Shukla VK, Ansari MA, Gupta SK. Wound healing research: a perspective fromIndia. Int J Lower Extrem Wounds 2005;4:7-8.

7. Rahman GA, Adigun IA, Fadeyi A. Epidemiology, etiology, and treatment of chronic leg ulcer: Experience with sixty patients. Ann Afr Med 2010;9:1-4

8. Nelzen O. Fifty percent reduction in venous ulcer prevalence is achievableSwedish experience. J Vasc Surg 2010;52:39S-44S.

9. Edwards H, Finlays K, Courtney M, et al. Health service pathways for patients 
with chronic leg ulcers: identifying effective pathways for facilitation of evidence based wound care. BMC Health services Research 2013;13:86.

10. Vuerstaek JD, Vainas T, Wuite J, et al. State of the art treatment of chronic leg ulcers: A randomized controlled trial comparing vacuum-assisted closure (V.A.C.) with modern wound dressings. J Vasc Surg. 2006;23.

11. Briggs M, Closs SJ. Patients' perceptions of the impact of treatments and products on their experience of leg ulcer pain. J Wound Care 2006;15:333-7.

12. Jorgensen B, Friis GJ, Gottrup F. Pain and quality of life for patients with venous leg ulcers: proof of concept of the efficacy of Biatain-Ibu, a new pain reducing wound dressing. Wound
Repair Regen 2006;14:233-9.

13. Wales S. A world of pain. Nurs Stand 2006;20:24-5.

14. Khan MN, Davies CG. Advances in the management of leg ulcers--the potential role of growth factors. Int Wound $\mathrm{J}$ 2006; 3:113-20.

15. Heinen MM, Persoon A, van de Kerkhof $\mathrm{P}$, et al. Ulcer related problems and health care needs in patients with venous leg ulceration: A descriptive, cross-sectional study. Int J Nurs Stud 2007;44:1296-303.

16. Bentley J. Improving quality of life in venous leg ulceration: a case study. $\mathrm{Br} \mathrm{J}$ Nurs 2006;15:S4-8.

17. Jones J, Barr W, Robinson J, Carlisle C. Depression in patients with chronic venous ulceration. $\mathrm{Br} J$ Nurs
2006;21:S17-23.

18. Gordon L, Edwards H, Courtney M, et al. A cost-effectiveness analysis of two community models of care for patients with venous leg ulcers. J Wound Care 2006;15:348-53.

19. Snyder RJ. Venous leg ulcers in the elderly patient: associated stress, social support, and coping. Ostomy Wound Manage 2006;52:58-66.

20. Oien RF, Ragnarson Tennvall G. Accurate diagnosis and effective treatment of leg ulcers reduce prevalence, care time and costs. J Wound Care 2006;15:259-62.

21. Furtado K, Pina E, Franks PJ, Moffatt CJ. Quality of life in patients with leg ulcers in Portugal. Rev Port Cir Cardiotorac Vasc 2005;12:169-74. 